\title{
Associations between tau, $A \beta$, and cortical thickness with cognition in Alzheimer disease
}

Rik Ossenkoppele, PhD, Ruben Smith, MD, PhD, Tomas Ohlsson, PhD, Olof Strandberg, PhD, Niklas Mattsson, MD, PhD, Philip S. Insel, MSc, Sebastian Palmqvist, MD, PhD, and Oskar Hansson, MD, PhD Neurology ${ }^{\circledR}$ 2019;92:e601-e612. doi:10.1212/WNL.0000000000006875

\author{
Correspondence \\ Dr. Ossenkoppele \\ r.ossenkoppele@vumc.nl \\ or Dr. Hansson \\ oskar.hansson@med.lu.se
}

\begin{abstract}
Objective

To examine the cross-sectional associations between regional tau, $\beta$-amyloid (A $\beta)$, and cortical thickness and neuropsychological function across the preclinical and clinical spectrum of Alzheimer disease $(\mathrm{AD})$.

\section{Methods}

We included 106 participants from the Swedish Biomarkers for Identifying Neurodegenerative Disorders Early and Reliably (BioFINDER) study, of whom 33 had preclinical AD (A $\beta$-positive cognitively normal individuals), 25 had prodromal $\mathrm{AD}$ ( $\mathrm{A} \beta$-positive mild cognitive impairment), and 48 had probable $\mathrm{AD}$ dementia. All underwent $\left[{ }^{18} \mathrm{~F}\right]$ flortaucipir (tau) and structural MRI (cortical thickness), and 88 of 106 underwent $\left[{ }^{18} \mathrm{~F}\right]$ flutemetamol (A $\beta$ ) PET. Linear regression models adjusted for age, sex, and education were performed to examine associations between 7 regions of interest and 7 neuropsychological tests for all 3 imaging modalities.
\end{abstract}

\section{Results}

In preclinical $\mathrm{AD},\left[{ }^{18} \mathrm{~F}\right]$ flortaucipir, but not $\left[{ }^{18} \mathrm{~F}\right]$ flutemetamol or cortical thickness, was associated with decreased global cognition, memory, and processing speed (range standardized $\beta=0.35-0.52, p<0.05$ uncorrected for multiple comparisons). In the combined prodromal $\mathrm{AD}$ and $\mathrm{AD}$ dementia group, both increased $\left[{ }^{18} \mathrm{~F}\right]$ flortaucipir uptake and reduced cortical thickness were associated with worse performance on a variety of neuropsychological tests (most regions of interest survived correction for multiple comparisons at $p<0.05$ ), while increased $\left[{ }^{18} \mathrm{~F}\right]$ flutemetamol uptake was specifically associated with lower scores on a delayed recall memory task $\left(p<0.05\right.$ uncorrected for multiple comparisons). The strongest effects for both $\left[{ }^{18} \mathrm{~F}\right]$ flortaucipir and cortical thickness on cognition were found in the lateral and medial parietal cortex and lateral temporal cortex. The effect of $\left[{ }^{18} \mathrm{~F}\right]$ flutemetamol on cognition was generally weaker and less region specific.

\section{Conclusion}

Our findings suggest that tau PET is more sensitive than A $\beta$ PET and measures of cortical thickness for detecting early cognitive changes in preclinical AD. Furthermore, both $\left[{ }^{18} \mathrm{~F}\right]$ flortaucipir PET and cortical thickness show strong cognitive correlates at the clinical stages of $\mathrm{AD}$. 


\section{Glossary}

$\mathbf{A} \beta=\beta$-amyloid $\mathbf{A D}=$ Alzheimer disease ADAS = Alzheimer's Disease Assessment Scale $\mathbf{A Q T}=\mathrm{A}$ Quick Test for Cognitive Speed; BioFINDER = Biomarkers for Identifying Neurodegenerative Disorders Early and Reliably; FDR = false discovery rate; MCI = mild cognitive impairment; MMSE = Mini-Mental State Examination; PVE = partial volume effects; ROI = region of interest; SUVR = standardized uptake value ratio; TMT-A = Trail Making Test A.

Alzheimer disease $(\mathrm{AD})$ has a long-lasting preclinical stage in which pathogenic proteins ( $\beta$-amyloid $[A \beta]$ and tau) aggregate and subtle structural and functional brain changes emerge without the co-occurrence of significant cognitive impairment. ${ }^{1-3}$ The accumulation of $A \beta$ is widespread relatively early in the disease course, while there is an ongoing accumulation of tau pathology and synaptic and neuronal loss, which corresponds to the clinical progression of the disease. ${ }^{4}$

Advances in the field of neuroimaging now allow in vivo whole-brain mapping of these pathophysiologic $(A \beta$ and tau deposition) and neurodegenerative (atrophy) processes, enabling detailed examination of their relationships with cognitive function. In line with the neuropathology literature, ${ }^{5}$ PET and MRI studies have shown intimate links between cognitive performance and both tau tracer retention and brain atrophy in $\mathrm{AD}$-specific regions. ${ }^{6-9}$ Although some variability exists across studies, especially cross-sectionally, the cognitive correlates for $A \beta$ pathology are generally weaker and less region specific. ${ }^{10-12}$

Identifying the contribution of the neurobiological hallmarks of $\mathrm{AD}$ to cognitive changes may inform design, participant selection, and monitoring of clinical trials. In the present study, we performed $\left[{ }^{18} \mathrm{~F}\right]$ flortaucipir PET (tau), $\left[{ }^{18} \mathrm{~F}\right]$ flutemetamol PET (A $\beta)$, structural MRI (cortical thickness), and a neuropsychological test battery in $106 \mathrm{~A} \beta$-positive patients with normal cognition, mild cognitive impairment (MCI), or $\mathrm{AD}$ dementia. We aimed to assess to what degree these imaging modalities were related to cognition and whether these relationships differed by disease stage (i.e., preclinical or clinical), specific neuropsychological function, or region of interest (ROI).

\section{Methods}

\section{Participants}

For this cross-sectional study, participants were recruited from the Swedish Biomarkers for Identifying Neurodegenerative Disorders Early and Reliably study (BioFINDER; biofinder.se). ${ }^{13}$ BioFINDER is a prospective study that focuses on identifying key mechanisms and improvement of diagnostics in $\mathrm{AD}$ and other neurodegenerative disorders. All participants underwent $\left[{ }^{18} \mathrm{~F}\right]$ flortaucipir PET, $\left[{ }^{18} \mathrm{~F}\right]$ flutemetamol PET (A $\beta)$, and structural MRI between June 2014 and November 2017. During this period, the majority of patients visiting the Memory Clinic and Clinical Memory Research Unit in Mälmo, Sweden, were invited to participate in the study. All underwent a medical history and complete neurologic examination, brain MRI, and neuropsychological testing. We included $33 \mathrm{~A} \beta$-positive cognitively normal individuals (called preclinical $\mathrm{AD}^{3}$ ), $25 \mathrm{~A} \beta$-positive patients with $\mathrm{MCI}$ (called prodromal $\mathrm{AD}^{14,15}$ ), and $48 \mathrm{~A} \beta$-positive patients with probable $\mathrm{AD}$ dementia. ${ }^{16}$ The preclinical $\mathrm{AD}$ groups consisted of both cognitively normal research volunteers $(n=17)$ and patients with subjective cognitive decline ${ }^{17}$ referred to the Memory Clinic of Skåne University Hospital in Sweden ( $\mathrm{n}=$ 8). In line with the "syndromal staging of the cognitive continuum" in the recently proposed research framework by the National Institute on Aging and the Alzheimer's Association, ${ }^{18}$ cognitively normal participants had a Clinical Dementia Rating score of 0, a Mini-Mental State Examination (MMSE) score between 27 and 30, and no history of cognitive change over time. All participants underwent $\left[{ }^{18} \mathrm{~F}\right]$ flortaucipir PET and structural MRI, while $\left[{ }^{18} \mathrm{~F}\right]$ flutemetamol PET was available in 86 of 106 (83\%) participants. A comparison between the baseline characteristics of the full BioFINDER study sample and the subsample with $\left[{ }^{18} \mathrm{~F}\right]$ flortaucipir PET and a flow diagram showing participant selection data are available from Dryad (table 1 and figure 1, doi. org/10.5061/dryad.ht92839).

\section{Standard protocol approvals, registrations, and patient consents}

The regional ethics committee at Lund University, the radiation protection committee at Skåne University Hospital, and the Swedish Medical Products Agency approved the study, and informed consent was obtained from all participants or their assigned surrogate decision makers.

\section{CSF biomarkers}

$A \beta$ status was determined with lumbar CSF sampling, performed following the Alzheimer's Association flowchart. ${ }^{19}$ Samples were stored in 1-mL polypropylene tubes at $-80^{\circ} \mathrm{C}$ until analysis. The samples were analyzed with commercially available ELISAs (INNOTEST, Fujirebio/Innogenetics, Ghent, Belgium) to determine the levels of total tau, $A \beta_{42}$, and phosphorylated tau. $A \beta$ positivity was defined as CSF $\mathrm{A} \beta_{42}<650 \mathrm{ng} / \mathrm{L}$. ${ }^{13}$ Board-certified laboratory technicians who were blinded to clinical data and diagnoses performed all analyses.

\section{Neuropsychological test battery}

Participants underwent a neuropsychological test battery covering major cognitive functions, including global cognition (MMSE), episodic memory (immediate and delayed word list recall tests from the Alzheimer's Disease Assessment Scale 
[ADAS] Cognitive Subscale), semantic memory (category [animal] fluency), language (naming condition of ADAS), and processing speed and attention (Trail Making Test A [TMT-A], A Quick Test for Cognitive Speed [AQT], form and color naming). Scores on ADAS tests were inverted so that higher values indicate better cognitive performance. For TMT-A and AQT, scores represent time needed to complete the task; thus, higher values indicate worse performance. TMT-A and AQT were log transformed to account for their nonnormal distribution. All participants had an MMSE score, but scores were missing for ADAS immediate recall $(\mathrm{n}=6)$, ADAS delayed recall $(\mathrm{n}=8)$, ADAS naming $(\mathrm{n}=$ $10)$, TMT-A $(n=9)$, animal fluency $(n=12)$, and AQT $(n=$ 14). Missing data were imputed with the fully conditional specification single-imputation method. ${ }^{20}$ This is an iterative Markov chain Monte Carlo method implemented in SPSS software (version 21) that can be used for arbitrary patterns of missing data. For each iteration (we allowed 25 iterations in total) and for each variable (we included the demographic, clinical, CSF, and imaging variables listed in tables 1 and 2), the fully conditional specification method fits a univariate model using all other available variables in the model as predictors and then imputes missing values for the variable being fit.

Characteristics of participants with missing data are provided in table 2 available from Dryad (doi.org/10.5061/ dryad.ht92839). To evaluate patterns of missingness, we performed binary logistic regression models with the demographic, clinical, and imaging variables listed in this table as predictors and missing cognitive data on each test (yes/ no) as the dependent variable. There were no associations between missing data on neuropsychological tests with any of the variables. In addition, the imputed dataset provided results highly similar to those of the original dataset (data not shown).

\section{MRI study}

T1-weighted MRI was performed on two 3.0T magnetic resonance scanners (Siemens Tim Trio $[\mathrm{n}=91,30$ with preclinical $\mathrm{AD}$ and 61 with clinical $\mathrm{AD}]$ and Siemens Skyra $[\mathrm{n}=15,3$ with preclinical $\mathrm{AD}$ and 12 with clinical $\mathrm{AD}]$,

Table 1 Demographic and clinical characteristics according to diagnostic group

\begin{tabular}{|c|c|c|c|c|c|c|}
\hline & $\begin{array}{l}\text { Preclinical } \\
\text { AD }(n=33)\end{array}$ & No. & $\begin{array}{l}\text { Prodromal } \\
A D(n=25)\end{array}$ & No. & $\begin{array}{l}\text { AD dementia } \\
(n=48)\end{array}$ & No. \\
\hline Age, y & $74.4 \pm 7.3$ & 33 & $73.1 \pm 7.2$ & 25 & $71.5 \pm 7.3$ & 48 \\
\hline Sex (male/female), $n$ & $13 / 20$ & 33 & $16 / 9$ & 25 & $26 / 22$ & 48 \\
\hline Education, y & $11.8 \pm 3.8$ & 33 & $12.7 \pm 3.5$ & 25 & $12.5 \pm 3.8$ & 47 \\
\hline$A \beta$ status, $\%$ positive & 100 & 33 & 100 & 25 & 100 & 48 \\
\hline APOE $\varepsilon 4$ status, $\%$ positive & 65.6 & 32 & 81.8 & 22 & 68.3 & 41 \\
\hline $\operatorname{CSF} A \beta_{42}{ }^{a}$ & $507 \pm 91$ & 33 & $435 \pm 102$ & 24 & $397 \pm 110$ & 46 \\
\hline CSF t-tau ${ }^{b}$ & $449 \pm 147$ & 33 & $627 \pm 186$ & 24 & $739 \pm 326$ & 46 \\
\hline CSF p-tau ${ }^{b}$ & $57 \pm 14$ & 33 & $77 \pm 19$ & 24 & $89 \pm 37$ & 46 \\
\hline MMSE score ${ }^{c}$ & $29.1 \pm 1.1$ & 33 & $25.6 \pm 2.8$ & 25 & $21.4 \pm 4.9$ & 48 \\
\hline ADAS immediate recall score ${ }^{\mathrm{d}, \mathrm{e}}$ & $7.3 \pm 1.4$ & 33 & $4.6 \pm 1.1$ & 23 & $3.9 \pm 1.6$ & 44 \\
\hline ADAS delayed recall score ${ }^{c, d}$ & $7.5 \pm 2.0$ & 33 & $3.7 \pm 2.3$ & 23 & $2.0 \pm 2.2$ & 42 \\
\hline TMT-A score ${ }^{f}$ & $52.8 \pm 19.7$ & 33 & $68.7 \pm 39.5$ & 22 & $104.8 \pm 82.1$ & 42 \\
\hline AQT (color and form) score ${ }^{e}$ & $65.5 \pm 15.5$ & 33 & $89.1 \pm 34.1$ & 22 & $102.9 \pm 34.9$ & 37 \\
\hline ADAS naming score ${ }^{d}$ & $11.2 \pm 1.9$ & 32 & $10.8 \pm 1.9$ & 21 & $9.9 \pm 2.8$ & 43 \\
\hline Verbal fluency score, animals $(1 \mathrm{~min})^{\mathrm{f}}$ & $20.8 \pm 5.7$ & 33 & $13.9 \pm 4.8$ & 24 & $11.0 \pm 5.7$ & 38 \\
\hline
\end{tabular}

Abbreviations: $A \beta=\beta$-amyloid; $A D=$ Alzheimer disease; $A D A S=$ Alzheimer's Disease Assessment Scale; $A Q T=A$ Quick Test of Cognitive Speed; $M M S E=$ MiniMental State Examination; $p$-tau = phosphorylated tau; TMT-A = Trail Making Test A; $t$-tau = total tau.

Differences in baseline characteristics between groups were assessed with analysis of variance with post hoc Bonferroni tests for continuous variables and $\chi^{2}$ and Kruskal-Wallis with post hoc Mann-Whitney $U$ tests for categorical or ordinal data. Number indicates the number of participants within each diagnostic group with the variable available. Note that missing neuropsychological data and education (for 1 patient with AD dementia) were imputed for further analysis.

a $A D$ dementia $<$ preclinical $A D, p<0.05$

${ }^{b} A D$ dementia $>$ preclinical $A D, p<0.001$, and prodromal $A D>$ preclinical $A D, p<0.05$.

${ }^{c} A D$ dementia/prodromal $A D<$ preclinical $A D, p<0.001$, and $A D$ dementia $<$ prodromal $A D, p<0.01$.

${ }^{d}$ Scores are inverted so that higher numbers indicate better performance.

e $A D$ dementia/prodromal $A D<$ preclinical $A D, p<0.01$.

${ }^{f} A D$ dementia $<$ prodromal $A D /$ preclinical $A D, p<0.05$. 
Table 2 Mean $\left[{ }^{18} \mathrm{~F}\right]$ flortaucipir, $\left[{ }^{18} \mathrm{~F}\right]$ flutemetamol, and cortical thickness and their correlations

\begin{tabular}{|c|c|c|c|c|c|c|}
\hline & $\begin{array}{l}{\left[{ }^{18} \mathrm{~F}\right]} \\
\text { flortaucipir } \\
\text { SUVR }\end{array}$ & $\begin{array}{l}{\left[{ }^{18} \mathrm{~F}\right]} \\
\text { flutemetamol } \\
\text { SUVR }\end{array}$ & $\begin{array}{l}\text { Cortical } \\
\text { thickness, mm }\end{array}$ & $\begin{array}{l}r \text {, Flortaucipir vs } \\
\text { flutemetamol }\end{array}$ & $\begin{array}{l}r \text {, Flortaucipir vs } \\
\text { thickness }\end{array}$ & $\begin{array}{l}r \text {, Flutemetamol vs } \\
\text { thickness }\end{array}$ \\
\hline \multicolumn{7}{|l|}{ Preclinical AD } \\
\hline No. & 33 & 30 & 33 & 30 & 33 & 33 \\
\hline Lateral parietal & $1.10 \pm 0.12$ & $0.86 \pm 0.16$ & $2.11 \pm 0.13$ & 0.20 & 0.08 & 0.03 \\
\hline Medial parietal & $1.08 \pm 0.08$ & $0.91 \pm 0.19$ & $2.12 \pm 0.11$ & 0.35 & -0.19 & 0.10 \\
\hline Lateral temporal & $1.16 \pm 0.11$ & $0.81 \pm 0.15$ & $2.48 \pm 0.14$ & $0.51^{\mathrm{b}, \mathrm{d}}$ & 0.02 & -0.02 \\
\hline Medial temporal & $1.11 \pm 0.17$ & $0.65 \pm 0.07$ & $2.89 \pm 0.21$ & $0.53^{\mathrm{b}, \mathrm{d}}$ & -0.03 & 0.24 \\
\hline Frontal & $1.05 \pm 0.07$ & $0.87 \pm 0.17$ & $2.28 \pm 0.13$ & 0.15 & 0.19 & -0.11 \\
\hline Occipital & $1.10 \pm 0.07$ & $0.73 \pm 0.11$ & $1.86 \pm 0.10$ & 0.30 & -0.15 & -0.11 \\
\hline Whole brain & $1.07 \pm 0.07$ & $0.82 \pm 0.14$ & $2.21 \pm 0.12$ & $0.37^{a}$ & 0.11 & 0.05 \\
\hline \multicolumn{7}{|l|}{$\begin{array}{l}\text { Prodromal } A D \text { and } \\
\text { AD dementia }\end{array}$} \\
\hline No. & 73 & 58 & 73 & 58 & 73 & 58 \\
\hline Lateral parietal & $1.63 \pm 0.55$ & $1.06 \pm 0.14$ & $1.98 \pm 0.14$ & 0.15 & $-0.54^{c, d}$ & -0.13 \\
\hline Medial parietal & $1.58 \pm 0.54$ & $1.13 \pm 0.17$ & $2.02 \pm 0.13$ & 0.13 & $-0.39^{\mathrm{b}, \mathrm{d}}$ & 0.02 \\
\hline Lateral temporal & $1.74 \pm 0.46$ & $1.00 \pm 0.15$ & $2.30 \pm 0.18$ & -0.03 & $-0.37^{b, d}$ & -0.07 \\
\hline Medial temporal & $1.53 \pm 0.25$ & $0.71 \pm 0.08$ & $2.44 \pm 0.28$ & -0.03 & -0.10 & 0.04 \\
\hline Frontal & $1.34 \pm 0.40$ & $1.09 \pm 0.16$ & $2.20 \pm 0.13$ & 0.02 & $-0.25^{a}$ & -0.06 \\
\hline Occipital & $1.45 \pm 0.37$ & $0.85 \pm 0.13$ & $1.82 \pm 0.11$ & $0.32^{a}$ & $-0.37^{\mathrm{b}, \mathrm{d}}$ & -0.16 \\
\hline Whole brain & $1.45 \pm 0.36$ & $1.00 \pm 0.13$ & $2.10 \pm 0.11$ & 0.03 & $-0.28^{a}$ & -0.10 \\
\hline
\end{tabular}

Abbreviations: AD = Alzheimer dementia; SUVR = standardized uptake value ratio.

Data presented are mean \pm SD for the imaging modalities and unadjusted correlation coefficients between modalities.

${ }^{a} p<0.05,{ }^{b} p<0.01,{ }^{c} p<0.001,{ }^{d} p<0.05$ after correction for multiple comparisons using the false discovery rate.

Siemens Medical Solutions, Erlangen, Germany), resulting in high-resolution anatomic magnetization-prepared rapid gradient-echo images (Tim Trio: repetition time 1,950 milliseconds, echo time 3.4 milliseconds, $1-\mathrm{mm}$ isotropic voxels, and 176 slices; Skyra: repetition time 1,900 milliseconds, echo time 2.5 milliseconds, 1 -mm isotropic voxels, and 176 slices). Cortical reconstruction and volumetric segmentation were performed with the FreeSurfer (version 5.3) image analysis pipelines (surfer.nmr.mgh.harvard. $\mathrm{edu} /$ ). Briefly, the magnetization-prepared rapid gradientecho images underwent correction for intensity homogeneity, ${ }^{21}$ removal of nonbrain tissue, ${ }^{22}$ and segmentation into gray matter and white matter with intensity gradient and connectivity among voxels. ${ }^{23}$ Cortical thickness was measured as the distance from the gray matter/white matter boundary to the corresponding pial surface. ${ }^{24}$ Reconstructed datasets were visually inspected for accuracy, and segmentation errors were corrected. Cortical thickness was determined for 7 predefined ROIs, including the medial and lateral parietal cortex, medial and lateral temporal cortex, frontal cortex, occipital cortex, and a whole-brain composite (including all cortical gray matter). Detailed composition of each ROI by FreeSurfer label is shown in table 3 available from Dryad (doi.org/10. 5061/dryad.ht92839).

\section{Tau and A $\beta$ PET}

$\left[{ }^{18} \mathrm{~F}\right]$ flortaucipir and $\left[{ }^{18} \mathrm{~F}\right]$ flutemetamol were synthesized at Skåne University Hospital, Lund, and PET scans were performed on a GE Discovery 690 PET scanner (General Electric Medical Systems, Chicago, IL) and a Philips Gemini TF 16 scanner (Philips Healthcare, Amsterdam, the Netherlands), respectively. $\left[{ }^{18} \mathrm{~F}\right]$ flortaucipir (previously known as $\left[{ }^{18} \mathrm{~F}\right]$ AV1451 or $\left.\left[{ }^{18} \mathrm{~F}\right] \mathrm{T} 807\right)$ is a PET tracer with high affinity to paired helical filaments of tau. The mean injected dose of $\left[{ }^{18} \mathrm{~F}\right]$ flortaucipir was $\approx 370 \mathrm{MBq}$, and participants underwent a PET scan during the 80- to 100 -minute interval after injection. Images were motion corrected with the AFNI $3 \mathrm{dvolreg}$, time averaged, and rigidly coregistered to the skullstripped MRI scan. Standardized uptake value ratio (SUVR) images for the interval between 80 and 100 seconds after injection were created with inferior cerebellar gray matter used as the reference region. ${ }^{25} \mathrm{We}$ additionally performed a correction for partial volume effects (PVE) using the 
Geomatric Transfer Matrix approach ${ }^{26}$ and report both uncorrected (main report) and corrected (available from Dryad, doi.org/10.5061/dryad.ht92839) data. For $\left[{ }^{18} \mathrm{~F}\right]$ flutemetamol, the mean injected dose was $\approx 185 \mathrm{MBq}$. PET images were acquired between 90 and 110 minutes after injection (4 $\times 5$ minute frames), and SUVR images for this time frame were computed with the pons used as the reference region.

FreeSurfer (version 5.3) parcellation of the T1-weighted MRI scan was applied to the PET data transformed to participants' native T1 space to extract mean regional SUVR values for each participant in the same 7 ROIs used for analyses of cortical thickness. $\left[{ }^{18} \mathrm{~F}\right]$ flutemetamol PET data were missing for 3 participants with preclinical $\mathrm{AD}, 7$ with prodromal $\mathrm{AD}$, and 8 with $\mathrm{AD}$ dementia. For 3 participants ( 1 with preclinical $\mathrm{AD}, 2$ with prodromal $\mathrm{AD}$ ) with missing $\mathrm{CSF}$ data, $\mathrm{A} \beta$ positivity was determined with $\left[{ }^{18} \mathrm{~F}\right]$ flutemetamol $\mathrm{SUVR}>0.69$ in a composite neocortical ROI. ${ }^{27}$

\section{Statistical analysis}

Differences in baseline characteristics between groups were assessed with analysis of variance with post hoc Bonferroni tests for continuous variables and $\chi^{2}$ and Kruskal-Wallis with post hoc Mann-Whitney $U$ tests for categorical or ordinal variables. Associations between $\left[{ }^{18} \mathrm{~F}\right]$ flortaucipir, $\left[{ }^{18} \mathrm{~F}\right]$ flutemetamol, and cortical thickness were examined with the (unadjusted) Pearson correlation analysis. Next, we performed linear regression models with an imaging ROI as the independent variable and a neuropsychological test score as the dependent variable while adjusting for age, sex, and education. These covariates were included on the basis of their established strong associations with cognitive performance. We did not control for MRI scanner type because the 2 Siemens scanners had highly similar properties and only 15 participants were scanned on the Siemens Skyra. The analyses were performed for each combination of ROI $(n=7)$, imaging modality $(n=3)$, and neuropsychological test $(n=7)$, and we stratified participants on the basis of preclinical (only cognitively normal individuals) or clinical (those with $\mathrm{MCI}$ and $\mathrm{AD}$ dementia combined) stage of $\mathrm{AD}$. We repeated these analyses using nonparametric linear regression models (adjusted for age, sex, and education) for all 3 imaging markers and using PVE-corrected data for $\left[{ }^{18} \mathrm{~F}\right]$ flortaucipir. We repeated the analyses for cortical thickness by adding MRI scanner type as an additional covariate. To provide more fine-grained regional information, we performed the analyses using all 68 (unilateral) FreeSurfer parcellations derived from the DesikanKilliany atlas. To assess whether the degree of asymmetry was related to specific neuropsychological functions, we repeated the aforementioned analyses using a left and right hemisphere composite of temporoparietal regions. Statistical significance was set at $p<0.05$. Because results were mostly in the same and expected direction, which reduces the likelihood of falsepositive findings, we indicated the level of significance both without and with correction for multiple comparisons using the Benjamini-Hochberg procedure with a false discovery rate (FDR) Q value of 5\%.

\section{Data availability}

Anonymized data will be shared by request from any qualified investigator for the sole purpose of replicating procedures and results presented in the article and as long as data transfer is in agreement with European Union legislation on the general data protection regulation.

\section{Results}

\section{Participants}

There were no significant differences in age, education, and sex between the preclinical, prodromal, and dementia groups. As expected, patients with $\mathrm{AD}$ dementia generally had the most severe biomarker or imaging abnormalities and worse cognitive performance, followed by those with prodromal $\mathrm{AD}$ and then those with preclinical $\mathrm{AD}$ (tables 1 and 2).

\section{Associations between $\left[{ }^{18} \mathrm{~F}\right]$ flortaucipir, $\left[{ }^{18} \mathrm{~F}\right]$ flortaucipir, and cortical thickness}

In preclinical $\mathrm{AD}$, regional correlations between $\left[{ }^{18} \mathrm{~F}\right]$ flortaucipir and $\left[{ }^{18} \mathrm{~F}\right]$ flutemetamol were observed in the medial and temporal cortical cortex and in the whole-brain composite ROI (range Pearson $r=0.37-0.53$, all $p<0.05$, table 2). In the prodromal $\mathrm{AD}$ and $\mathrm{AD}$ dementia group, $\left[{ }^{18} \mathrm{~F}\right]$ flortaucipir and $\left[{ }^{18} \mathrm{~F}\right]$ flutemetamol SUVRs were correlated in the occipital cortex (Pearson $r=0.32, p<0.05$, table 2). There was an association between $\left[{ }^{18} \mathrm{~F}\right]$ flortaucipir and cortical thickness in all ROIs (range Pearson $r=0.25-0.54$, all $p<0.05$ ), except for the medial temporal lobe. There were no regional associations between $\left[{ }^{18} \mathrm{~F}\right]$ flutemetamol and cortical thickness for any of the diagnostic groups (table 2).

\section{Preclinical AD}

Linear regression models adjusted for age, sex, and education in the preclinical $\mathrm{AD}$ group showed associations between increased $\left[{ }^{18} \mathrm{~F}\right]$ flortaucipir uptake and worse performance on the ADAS immediate recall (lateral and medial parietal cortex, lateral temporal cortex, and whole brain), ADAS delayed recall (lateral parietal cortex), MMSE (medial temporal cortex), and TMT-A (medial parietal cortex, lateral temporal cortex, frontal cortex, and whole-brain) (table 3 and figure 1). None of these associations survived FDR correction for multiple comparisons. There were no significant associations between regional cortical thickness or $\left[{ }^{18} \mathrm{~F}\right]$ flutemetamol uptake and any of the neuropsychological tests (table 3 and figure 1). Analyses for all 3 imaging markers using nonparametric regression models and PVE-corrected $\left[{ }^{18} \mathrm{~F}\right]$ flortaucipir data yielded largely similar results (tables 4 and 5 available from Dryad, doi.org/ 10.5061/dryad.ht92839). Cortical thickness in the medial parietal and occipital cortex was significantly associated with TMA-A when additionally adjusted for MRI scanner type, while all other associations remained nonsignificant (table 6 available from Dryad). The associations between all 68 (unilateral) FreeSurfer parcellations and cognition are shown in table 7 available from Dryad. 
Table 3 Associations between $\left[{ }^{18} \mathrm{~F}\right]$ flortaucipir, $\left[{ }^{18} \mathrm{~F}\right]$ flutemetamol, and cortical thickness and cognition in preclinical AD

\begin{tabular}{|c|c|c|c|c|c|c|c|}
\hline & $\begin{array}{l}\text { MMSE } \\
\text { score }\end{array}$ & $\begin{array}{l}\text { ADAS immediate } \\
\text { recall score }\end{array}$ & $\begin{array}{l}\text { ADAS delayed } \\
\text { recall score }\end{array}$ & $\begin{array}{l}\text { TMT-A } \\
\text { score }\end{array}$ & $\begin{array}{l}\text { AQT } \\
\text { score }\end{array}$ & $\begin{array}{l}\text { ADAS } \\
\text { naming score }\end{array}$ & $\begin{array}{l}\text { Animal } \\
\text { fluency score }\end{array}$ \\
\hline \multicolumn{8}{|c|}{$\left[{ }^{18}\right.$ F]flortaucipir $(n=33)$} \\
\hline Lateral parietal & -0.08 & $-0.51^{b}$ & $-0.39^{a}$ & 0.24 & -0.08 & -0.06 & -0.22 \\
\hline Medial parietal & -0.19 & $-0.52^{b}$ & -0.30 & $0.39^{a}$ & 0.11 & 0.02 & 0.10 \\
\hline Lateral temporal & -0.23 & $-0.40^{\mathrm{a}}$ & -0.26 & $0.39^{a}$ & 0.14 & -0.05 & -0.20 \\
\hline Medial temporal & $-0.45^{a}$ & -0.22 & -0.16 & $0.35^{\mathrm{a}}$ & 0.27 & 0.04 & -0.09 \\
\hline Frontal & -0.05 & -0.36 & -0.33 & $0.39^{a}$ & -0.09 & -0.13 & -0.21 \\
\hline Occipital & -0.22 & -0.28 & -0.25 & 0.32 & 0.00 & -0.16 & 0.05 \\
\hline Whole brain & -0.15 & $-0.42^{\mathrm{a}}$ & -0.32 & $0.39^{a}$ & 0.01 & -0.10 & -0.16 \\
\hline \multicolumn{8}{|c|}{$\left[{ }^{18} \mathrm{~F}\right]$ flutemetamol $(n=30)$} \\
\hline Lateral parietal & -0.11 & -0.14 & 0.04 & 0.02 & 0.19 & -0.12 & -0.04 \\
\hline Medial parietal & -0.14 & -0.15 & 0.06 & -0.13 & 0.13 & -0.09 & -0.07 \\
\hline Lateral temporal & -0.15 & -0.12 & 0.08 & 0.05 & 0.24 & 0.02 & -0.08 \\
\hline Medial temporal & 0.01 & -0.19 & 0.07 & 0.06 & 0.29 & -0.07 & -0.07 \\
\hline Frontal & -0.26 & -0.13 & 0.01 & -0.13 & 0.15 & -0.03 & -0.04 \\
\hline Occipital & 0.05 & -0.13 & 0.13 & 0.15 & 0.25 & -0.09 & -0.14 \\
\hline Whole brain & -0.15 & -0.14 & 0.06 & -0.03 & 0.18 & -0.05 & -0.06 \\
\hline \multicolumn{8}{|c|}{ Cortical thickness $(n=33)$} \\
\hline Lateral parietal & 0.26 & 0.21 & 0.03 & -0.06 & -0.15 & -0.25 & 0.02 \\
\hline Medial parietal & 0.16 & 0.19 & -0.08 & -0.31 & -0.32 & -0.20 & 0.01 \\
\hline Lateral temporal & 0.07 & 0.12 & -0.03 & -0.19 & 0.00 & -0.31 & -0.02 \\
\hline Medial temporal & -0.14 & 0.07 & 0.09 & -0.10 & 0.18 & 0.01 & 0.06 \\
\hline Frontal & 0.15 & 0.15 & -0.03 & 0.03 & 0.01 & 0.26 & 0.08 \\
\hline Occipital & 0.20 & 0.21 & 0.13 & -0.24 & -0.01 & -0.18 & 0.04 \\
\hline Whole brain & 0.18 & 0.18 & 0.03 & -0.13 & -0.05 & -0.25 & 0.02 \\
\hline
\end{tabular}

Abbreviations: $\mathrm{AD}$ = Alzheimer dementia; $\mathrm{ADAS}=$ Alzheimer's Disease Assessment Scale; $\mathrm{AQT}$ = A Quick Test of Cognitive Speed; MMSE = Mini-Mental State Examination; TMT-A = Trail Making Test $\mathrm{A}$.

Data presented are standardized $\beta$ coefficients derived from linear regression models adjusted for age, sex, and education. TMT-A and AQT were logtransformed before statistical analysis.

${ }^{\mathrm{a}} p<0.05,{ }^{\mathrm{b}} p<0.01$ (both uncorrected for multiple comparisons).

\section{Prodromal AD and AD dementia}

Table 3 presents the standardized $\beta$ coefficients resulting from linear regression models in the combined prodromal $\mathrm{AD}$ and $\mathrm{AD}$ dementia group. Regional $\left[{ }^{18} \mathrm{~F}\right]$ flortaucipir SUVR and cortical thickness showed strong associations with cognition across all neuropsychological tests (table 4 and figure 2). For both $\left[{ }^{18} \mathrm{~F}\right]$ flortaucipir and cortical thickness, standardized $\beta$ coefficients were generally higher in temporoparietal regions compared to frontal, occipital, or whole-brain ROIs. Furthermore, for most neuropsychological tests (especially episodic memory tasks), the associations with cognition were slightly stronger for $\left[{ }^{18} \mathrm{~F}\right]$ flortaucipir than for cortical thickness (with the exception of the AQT, table 4). For $\left[{ }^{18} \mathrm{~F}\right]$ flutemetamol, increased uptake was associated with lower scores on the ADAS delayed recall for all ROIs except the occipital cortex (table 4), while occipital $\left[{ }^{18} \mathrm{~F}\right]$ flutemetamol retention was associated with worse performance on tasks involving processing speed and attention (i.e., TMT-A and AQT). For $\left[{ }^{18} \mathrm{~F}\right]$ flortaucipir and cortical thickness, several associations with cognition survived FDR correction for multiple comparisons but not for $\left[{ }^{18} \mathrm{~F}\right]$ flutemetamol (table 4).

Results are also provided for the separate diagnostic groups in table 8 (prodromal $\mathrm{AD}$ ) and table 9 ( $\mathrm{AD}$ dementia) available from Dryad (doi.org/10.5061/dryad.ht92839). Results for prodromal $\mathrm{AD}$ and $\mathrm{AD}$ dementia groups were mostly comparable to 
A. Lateral parietal
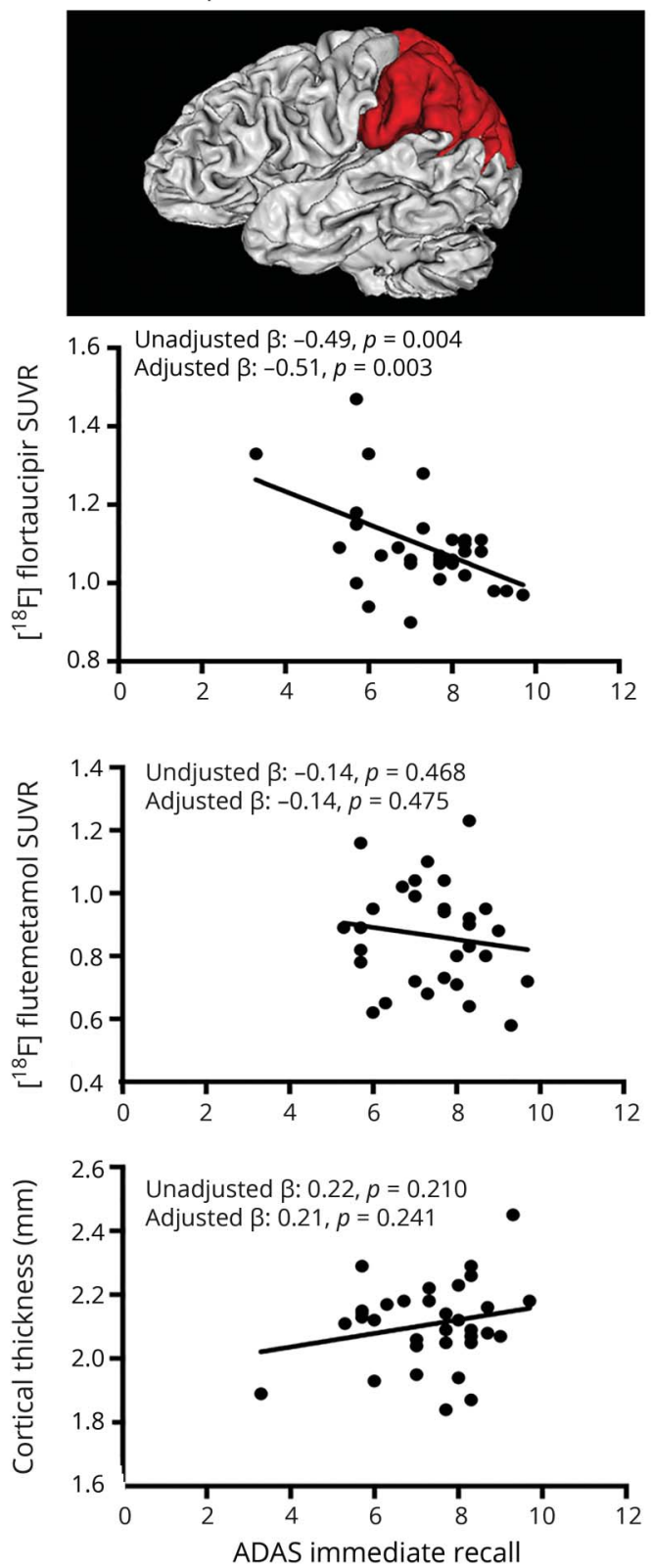

B. Whole brain
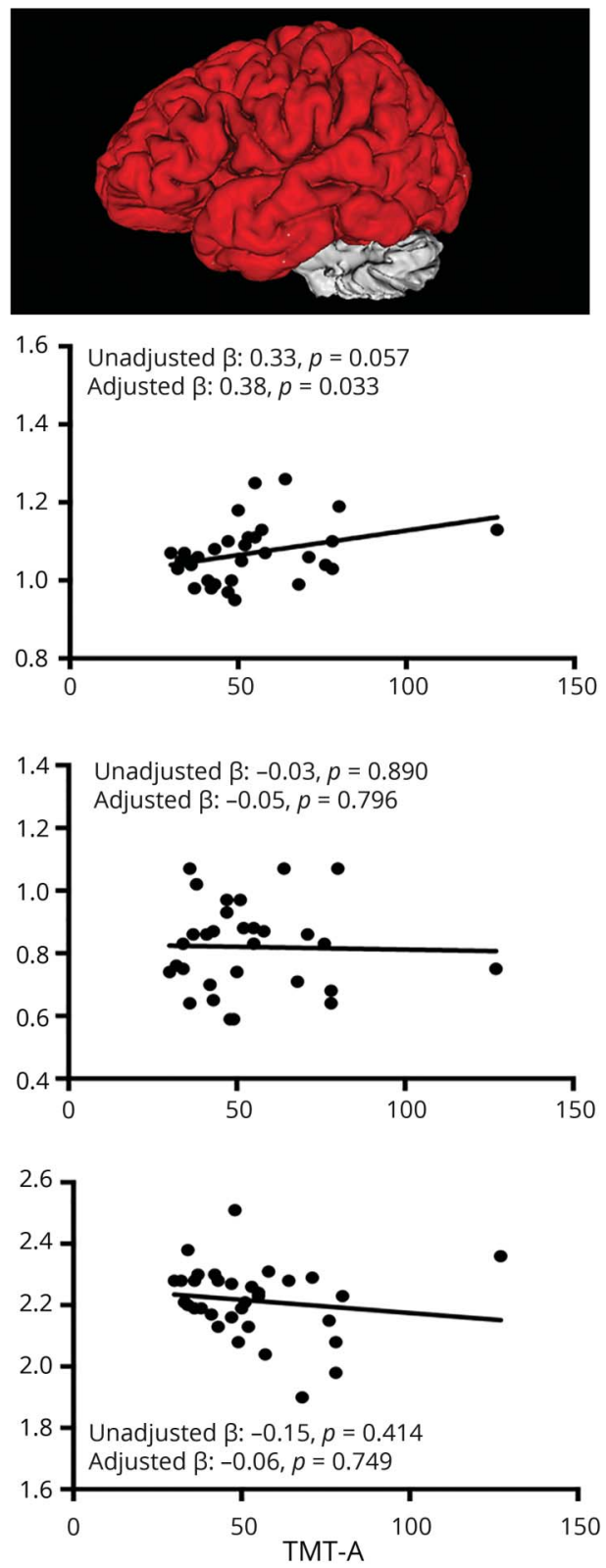

(A) Lateral parietal region of interest (ROI) for each imaging modality vs Alzheimer's Disease Assessment Scale (ADAS) immediate recall scores. (B) Whole-brain ROI vs Trail Making Test A (TMT-A) (log-transformed for statistical analysis, but original data are shown here). Bs are standardized and presented with and without adjustment for age, sex, and education. SUVR = standardized uptake value ratio.

those of the combined group in terms of direction (figure 2) and strength of the effect sizes but were less (often) significant because of reduced statistical power related to smaller sample sizes. Repeating the analysis for $\left[{ }^{18} \mathrm{~F}\right]$ flortaucipir using PVE corrected data resulted in weaker associations with MMSE and ADAS memory and language tests and yielded comparable associations with TMT, AQT, and animal fluency (table 5 available from Dryad). Analyses for all 3 imaging markers using nonparametric regression models (table 10 available from Dryad) yielded largely similar results compared to its parametric counterpart reported in table 4 . When MRI scanner type was added as an additional covariate to the model, the associations between cortical thickness and cognition remained virtually the same (table 6 available from Dryad). The associations between all 68 (unilateral) FreeSurfer parcellations and cognition are given in table 7 available from Dryad.

\section{Lateralization}

In preclinical $\mathrm{AD}$, associations between $\left[{ }^{18} \mathrm{~F}\right]$ flortaucipir uptake and cognition were more pronounced in the left temporoparietal cortex than in the right temporoparietal cortex for ADAS immediate recall (standardized $\beta$ coefficient -0.57 
Table 4 Associations between $\left[{ }^{18} \mathrm{~F}\right]$ flortaucipir, $\left[{ }^{18} \mathrm{~F}\right]$ flutemetamol, and cortical thickness and cognition in prodromal AD and AD dementia

\begin{tabular}{|c|c|c|c|c|c|c|c|}
\hline & $\begin{array}{l}\text { MMSE } \\
\text { score }\end{array}$ & $\begin{array}{l}\text { ADAS immediate } \\
\text { recall score }\end{array}$ & $\begin{array}{l}\text { ADAS delayed } \\
\text { recall score }\end{array}$ & $\begin{array}{l}\text { TMT-A } \\
\text { score }\end{array}$ & $\begin{array}{l}\text { AQT } \\
\text { score }\end{array}$ & $\begin{array}{l}\text { ADAS } \\
\text { naming score }\end{array}$ & $\begin{array}{l}\text { Animal } \\
\text { fluency score }\end{array}$ \\
\hline \multicolumn{8}{|c|}{$\left[{ }^{18}\right.$ F]flortaucipir $(n=73)$} \\
\hline Lateral parietal & $-0.32^{\mathrm{a}, \mathrm{d}}$ & -0.12 & -0.22 & $0.55^{c, d}$ & $0.33^{a, d}$ & -0.20 & $-0.41^{b, d}$ \\
\hline Medial parietal & $-0.28^{a}$ & -0.26 & $-0.30^{\mathrm{a}}$ & $0.47^{b, d}$ & $0.30^{a}$ & $-0.31^{a}$ & $-0.48^{\mathrm{b}, \mathrm{d}}$ \\
\hline Lateral temporal & $-0.34^{\mathrm{a}, \mathrm{d}}$ & $-0.31^{\mathrm{a}, \mathrm{d}}$ & $-0.35^{\mathrm{b}, \mathrm{d}}$ & $0.35^{b, d}$ & 0.17 & $-0.38^{\mathrm{b}, \mathrm{d}}$ & $-0.45^{\mathrm{b}, \mathrm{d}}$ \\
\hline Medial temporal & $-0.25^{a}$ & $-0.31^{a, d}$ & $-0.32^{a, d}$ & 0.05 & -0.02 & -0.22 & $-0.25^{\mathrm{a}}$ \\
\hline Frontal & $-0.37^{b, d}$ & $-0.46^{b, d}$ & $-0.33^{\mathrm{a}, \mathrm{d}}$ & 0.17 & 0.08 & $-0.51^{\mathrm{c}, \mathrm{d}}$ & $-0.53^{c, d}$ \\
\hline Occipital & -0.20 & -0.07 & $-0.27^{a}$ & $0.48^{c, d}$ & 0.23 & 0.05 & $-0.29^{a, d}$ \\
\hline Whole brain & $-0.36^{\mathrm{b}, \mathrm{d}}$ & $-0.33^{a, d}$ & $-0.33^{\mathrm{a}, \mathrm{d}}$ & $0.41^{b, d}$ & 0.22 & $-0.36^{a, d}$ & $-0.50^{c, d}$ \\
\hline \multicolumn{8}{|c|}{$\left[{ }^{18}\right.$ F]flutemetamol $(n=58)$} \\
\hline Lateral parietal & -0.21 & -0.02 & $-0.33^{a}$ & 0.15 & 0.16 & -0.05 & -0.02 \\
\hline Medial parietal & -0.15 & -0.10 & $-0.35^{b}$ & 0.05 & 0.03 & -0.09 & 0.02 \\
\hline Lateral temporal & -0.24 & -0.09 & $-0.37^{b}$ & 0.01 & 0.10 & -0.07 & 0.03 \\
\hline Medial temporal & -0.26 & -0.03 & $-0.30^{a}$ & -0.04 & -0.03 & -0.04 & -0.01 \\
\hline Frontal & -0.23 & -0.09 & $-0.29^{a}$ & 0.04 & 0.06 & -0.07 & 0.03 \\
\hline Occipital & -0.15 & -0.05 & -0.25 & $0.27^{a}$ & $0.24^{a}$ & 0.08 & -0.08 \\
\hline Whole brain & -0.23 & -0.08 & $-0.33^{a}$ & 0.09 & 0.12 & -0.05 & 0.01 \\
\hline \multicolumn{8}{|c|}{ Cortical thickness $(n=73)$} \\
\hline Lateral parietal & $0.31^{a, d}$ & 0.00 & 0.16 & $-0.36^{b, d}$ & $-0.41^{c, d}$ & 0.00 & 0.24 \\
\hline Medial parietal & 0.21 & -0.08 & 0.06 & $-0.34^{b, d}$ & $-0.44^{\mathrm{c}, \mathrm{d}}$ & -0.02 & 0.16 \\
\hline Lateral temporal & $0.32^{b, d}$ & 0.14 & $0.25^{\mathrm{a}}$ & -0.23 & $-0.30^{b, d}$ & $0.25^{\mathrm{a}}$ & $0.38^{b, d}$ \\
\hline Medial temporal & $0.40^{b, d}$ & $0.28^{a}$ & $0.37^{b, d}$ & -0.07 & -0.16 & 0.16 & $0.37^{b, d}$ \\
\hline Frontal & $0.25^{\mathrm{a}}$ & 0.15 & 0.07 & -0.01 & -0.07 & 0.14 & $0.35^{b, d}$ \\
\hline Occipital & 0.13 & -0.16 & 0.13 & $-0.33^{b, d}$ & $-0.35^{\mathrm{b}, \mathrm{d}}$ & -0.10 & 0.06 \\
\hline Whole brain & $0.32^{b, d}$ & 0.09 & 0.18 & -0.23 & $-0.29^{b, d}$ & 0.13 & $0.34^{b, d}$ \\
\hline
\end{tabular}

Abbreviations: $\mathrm{AD}=$ Alzheimer dementia; $\mathrm{ADAS}=$ Alzheimer's Disease Assessment Scale; $\mathrm{AQT}$ = A Quick Test of Cognitive Speed; MMSE = Mini-Mental State Examination; TMT-A = Trail Making Test A.

Data presented are standardized $\beta$ coefficients derived from linear regression models adjusted for age, sex and education. TMT-A and AQT were logtransformed prior to statistical analysis.

${ }^{a} p<0.05,{ }^{b} p<0.01,{ }^{c} p<0.001,{ }^{d} p<0.05$ after correction for multiple comparisons using the false discovery rate.

vs -0.37$)$ and for ADAS delayed recall $(-0.40$ vs -0.25$)$. There were no clear asymmetric relationships for temporoparietal $\left[{ }^{18} \mathrm{~F}\right]$ flortaucipir uptake with any of the other neuropsychological tests or for temporoparietal $\left[{ }^{18} \mathrm{~F}\right]$ flutemetamol or cortical thickness (table 11 available from Dryad, doi.org/10.5061/dryad.ht92839). For prodromal $\mathrm{AD}$ and $\mathrm{AD}$ dementia, $\left[{ }^{18} \mathrm{~F}\right]$ flortaucipir uptake and cortical thickness were strongly related to ADAS naming in the left temporoparietal cortex but not the right temporoparietal cortex (figure 3). There were no clear asymmetric findings for the other neuropsychological tests, and $\left[{ }^{18} \mathrm{~F}\right]$ flutemetamol showed comparable results for left vs right temporoparietal cortex (table 12 available from Dryad).

\section{Discussion}

In this study, we examined the cross-sectional associations between tau, $A \beta$, and cortical thickness and neuropsychological function across $A \beta$-positive individuals at the preclinical and clinical stages of $\mathrm{AD}$. In the preclinical $\mathrm{AD}$ group, we found associations with cognition only for tau PET but not for A $\beta$ PET or cortical thickness. In prodromal $\mathrm{AD}$ and $\mathrm{AD}$ dementia, we found strong relationships between increased tau pathology and reduced cortical thickness with worse performance on a wide variety of neuropsychological tests. These relationships were most pronounced in bilateral temporoparietal regions. $\mathrm{A} \beta \mathrm{pa}$ thology was specifically related to decreased delayed recall on 


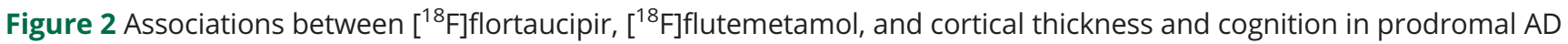
and $A D$ dementia

\section{A. Lateral temporal}
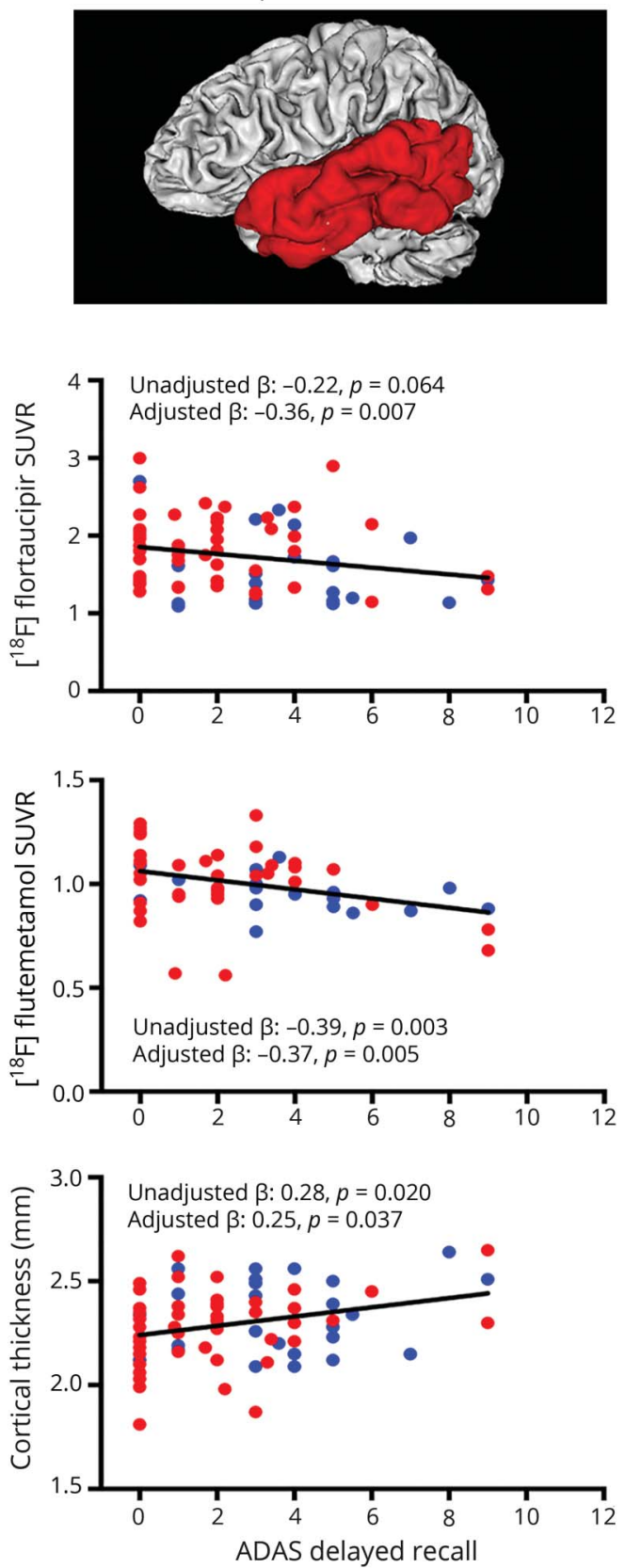

B. Whole brain

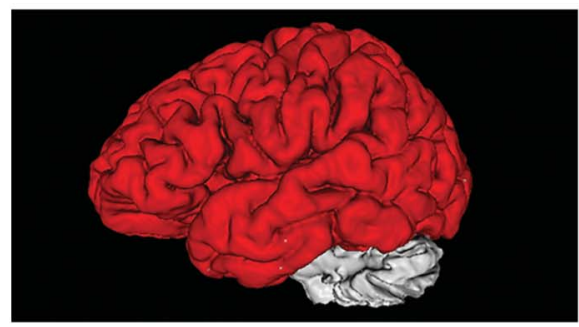

Prodromal AD
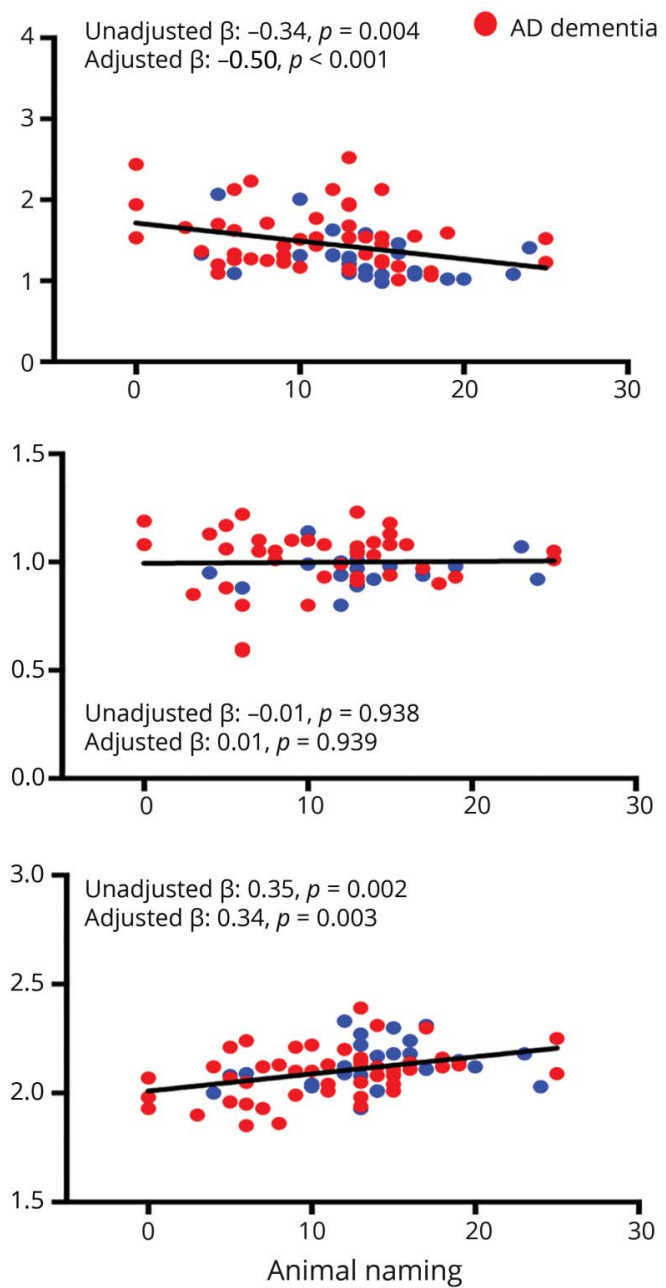

(A) Lateral temporal region of interest (ROI) for each imaging modality vs Alzheimer's Disease Assessment Scale (ADAS) delayed recall scores. (B) Whole-brain ROI vs performance on animal fluency. $\beta$ s are standardized and presented with and without adjustment for age, sex, and education. AD = Alzheimer dementia; SUVR = standardized uptake value ratio.

a word list learning task and showed limited regional specificity. These findings suggest that $\left[{ }^{18} \mathrm{~F}\right]$ flortaucipir PET is the most sensitive of these markers for detecting early changes in cognitive function, while both $\left[{ }^{18} \mathrm{~F}\right]$ flortaucipir PET and cortical thickness show strong cognitive correlates at the clinical stages of $\mathrm{AD}$.

A main finding in the present study was that regional tau PET was related to cognitive function already in cognitively normal $\mathrm{A} \beta$-positive individuals in the absence of similar effects for cortical thickness and $A \beta$ pathology. This is in line with earlier clinicopathologic $^{5,28}$ and imaging studies ${ }^{29,30}$ in preclinical stages of $\mathrm{AD}$ showing intimate links between tau pathology and cognition. The lack of an effect for $A \beta$ pathology could be explained by the estimated time interval of $\approx 15$ to 20 years between its pathologic beginnings and symptom onset. ${ }^{1,31}$ Relationships between reductions in cortical thickness are less affected by this separation in space and time as observed for $A \beta$ pathology. ${ }^{32,33}$ Cortical thickness, however, is 
A

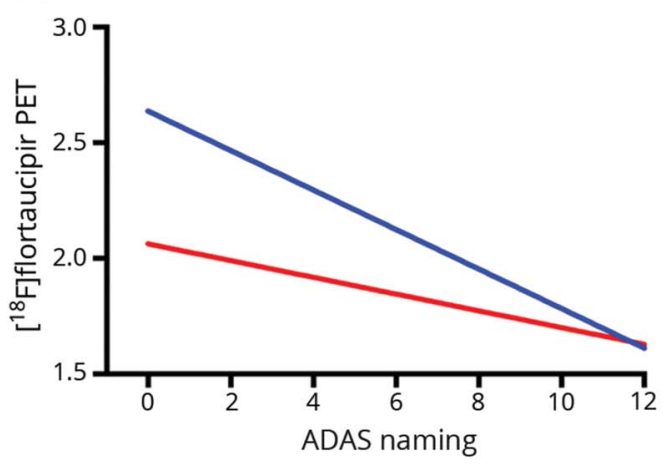

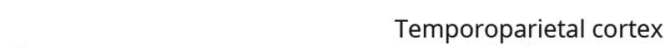
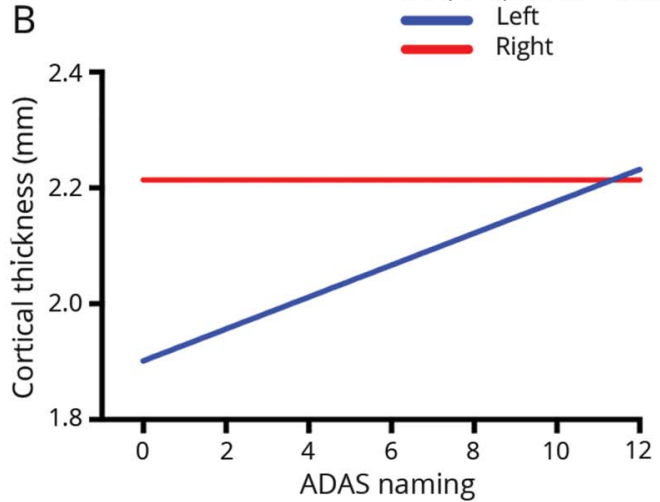

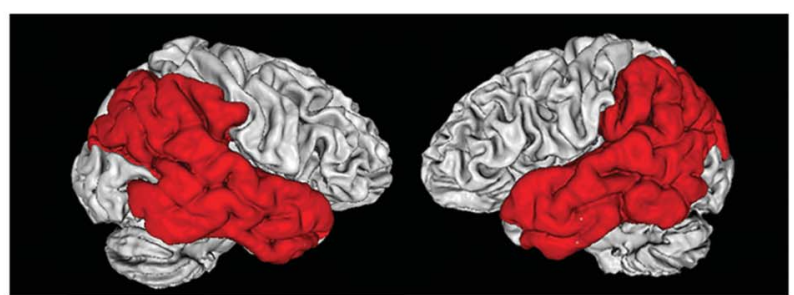

Stronger relationships with Alzheimer's Disease Assessment Scale (ADAS) object naming for left temporoparietal cortex (A) [ $\left.{ }^{18} \mathrm{~F}\right]$ flortaucipir uptake and (B) cortical thickness compared to the right temporoparietal cortex. $\beta$ s are standardized and presented adjusted for age, sex, and education.

characterized by substantial preexisting variation among individuals, which might reduce the sensitivity for separating the earliest $\mathrm{AD}$-related changes from age-related brain changes. Furthermore, tau pathology might be present before neurodegeneration starts 4,34 and might exert its effects on cognition through both structural ${ }^{35}$ (i.e., cortical thickness reductions) and functional ${ }^{36,37}$ (i.e., synaptic alterations) pathways. This finding has potential ramifications for clinical trials in that tau PET might be superior to the other measures for identifying individuals at risk for future cognitive decline and for tracking cognitive trajectories during treatment with disease-modifying drugs.

At the clinical stages of $\mathrm{AD}$ (i.e., prodromal $\mathrm{AD}$ and $\mathrm{AD}$ dementia), regional patterns of both tau pathology and cortical thickness showed strong associations with cognitive function. This finding in a cohort of patients with mostly lateonset $\mathrm{AD}$ with memory-predominant presentations is in line with previous tau PET studies characterized by an on average young age at onset and often atypical presentation. $6,7,38$ Compared to the preclinical stages of $\mathrm{AD}$, the effects of tau PET were considerably stronger and were present across all neuropsychological tests and ROIs, although there was a temporoparietal predominance (table 3). The latter is in agreement with the composition of our neuropsychological test battery (which did not include a specific frontal test) in combination with the localization of tau pathology, which typically strongly occupies temporoparietal regions in $\mathrm{AD}$. The effects of cortical thickness vs tau PET results were overall comparable, although slightly weaker for cortical thickness on memory domains and slightly stronger on a task involving processing speed. Although our models were set up to test cognition-imaging correlates at a group level and not to make individual predictions, the results open the possibility that both tau PET and cortical thickness have potential utility for clinical use (i.e., diagnosis or prognosis) at clinical stages of the disease and for patient selection and monitoring of clinical trials.

In line with the assumptions of a hypothetical biomarker model, ${ }^{4}$ the relationships between $A \beta$ pathology and cognition at the clinical stages of $\mathrm{AD}$ were modest at best. The rate of accumulation of $A \beta$ pathology is thought to attenuate or even plateau at the time when clinical symptoms have emerged, and at that point, $\mathrm{A} \beta$ pathology has spread out into nearly the entire neocortex. It has therefore been argued that A $\beta$ pathology might be triggering tau pathology to spread from entorhinal cortex to neocortical areas and that this event is the actual driver of cognitive loss. ${ }^{39,40}$ Consequently, A $\beta$ pathology is often not or only modestly related to cognitive performance, ${ }^{10,12,41}$ although there are some exceptions in very young patients with $\mathrm{AD}^{42}$ or atypical variants of $\mathrm{AD} .^{43} \mathrm{In}$ the present study, the effects of $A \beta$ pathology were much weaker compared to those of tau pathology and cortical thickness, but we found significant associations between $\mathrm{A} \beta$ PET and episodic memory (delayed recall) in almost all neocortical areas. This could be explained by the complexity of this task; previous research has shown that cognitively demanding tests may be required to capture the subtle effects of $A \beta$ pathology on cognition. ${ }^{44}$ Furthermore, if effects of $A \beta$ 
pathology on cognition are shown, they typically involve memory function. The reason could be that this is usually the most impaired cognitive domain in patients with $\mathrm{AD}$ or with $A \beta$ pathology initially spreading through posterior parts of the default mode network, ${ }^{45,46}$ which could be affecting memory function through its strong connections with medial temporal lobe structures. ${ }^{47}$ Occipital $A \beta$ load was associated with reduced processing speed and attention. Because the occipital cortex is among the brain regions affected by $\mathrm{A} \beta$ deposition in late stages, this could reflect a more advanced disease stage. Alternatively, the occipital signal may reflect the presence of cerebral amyloid angiopathy, which has a predilection for the occipital cortex ${ }^{48}$ and is associated with mental slowness and attentional deficits. ${ }^{49}$

A strength of this study is that we combined 3 imaging modalities in combination with a neuropsychological test battery in individuals across the $\mathrm{AD}$ spectrum. There are also some limitations. First, although our neuropsychological battery included tests commonly used in clinical studies and trials, we did not capture all cognitive domains. In particular, tests for visuospatial and some executive functions were missing. Second, A $\beta$ PET was missing in 18 (17\%) participants. Third, the sample size differed between analyses in preclinical $(\mathrm{n}=$ $33)$ and clinical $(n=73)$ stages. Interpretation was therefore focused on effect size (not affected by sample size) and level of significance (affected by sample size). Fourth, $\left[{ }^{18} \mathrm{~F}\right]$ flortaucipir is still a relatively new tracer; thus, only a few antemortem vs postmortem comparisons have been reported, and its binding properties are not yet fully understood. Factors that could affect the accuracy of the signal include off-target binding (e.g., to monoamine oxidase B, neuromelanin, or vascular lesions) and the continued increase in specific tracer binding after the duration of the PET scan. ${ }^{50}$ Fifth, it is possible that some patients had comorbid pathologies such as $\alpha$-synuclein, TAR DNA-binding protein 43 , or vascular pathology, which were not examined. The presence of such comorbid conditions may potentially attenuate the associations between cognitive scores and biomarkers of tau, $A \beta$, and cortical thickness.

We found that tau PET is a more sensitive marker for detecting the earliest cognitive changes in $\mathrm{AD}$ than $\mathrm{A} \beta$ PET and cortical thickness measures. In clinical stages, both regional tau PET and cortical thickness measures showed strong cognitive correlates, while A $\beta$ PET showed weaker and less region-specific associations with cognition. Future studies should include longitudinal assessments of both neuropsychological scores and neuroimaging to determine which modality is most suited for predicting and monitoring cognitive changes over time. Furthermore, the overlapping and complementary effects of tau and brain atrophy on cognition should be further investigated, ${ }^{7}$ and ROIs have to be refined. Identifying the contribution of these neurobiological hallmarks of $\mathrm{AD}$ to cognitive changes could eventually improve the diagnostic and prognostic process in $\mathrm{AD}$ and may inform design, participant selection, and monitoring of clinical trials.

\section{Author contributions}

R.O. contributed to study design, analysis, and interpretation of data, writing and revising the manuscript, and performed statistical analysis. T.O. and O.S. contributed to the acquisition and analysis of data. R.S., N.M., P.S.I., and S.P. critically revised the manuscript for intellectual content. O.H. contributed to study concept and design, acquisition of patient data from the Swedish BioFINDER study, interpretation of data, critical revision of the manuscript for intellectual content, and supervised the study.

\section{Acknowledgment}

The authors thank Colin Groot for support with the figures.

\section{Study funding}

Work at Lund University was supported by the European Research Council, the Swedish Research Council, the Marianne and Marcus Wallenberg foundation, the Strategic Research Area MultiPark (Multidisciplinary Research in Parkinson's disease) at Lund University, the Swedish Brain Foundation, the Swedish Alzheimer Foundation, The Parkinson Foundation of Sweden, The Parkinson Research Foundation, the Skåne University Hospital Foundation, and the Swedish federal government under the ALF agreement. Doses of ${ }^{18} \mathrm{~F}$-flutemetamol injection were sponsored by GE Healthcare, and the precursor of $\left[{ }^{18} \mathrm{~F}\right]$ flortaucipir was provided by AVID Radiopharmaceuticals.

\section{Disclosure}

R. Ossenkoppele, R. Smith, T. Ohlsson, O. Strandberg, N. Mattsson, P. Insel, and S. Palmqvist report no disclosures relevant to the manuscript. O. Hansson has acquired research support (for the institution) from Roche, GE Healthcare, Biogen, AVID Radiopharmaceuticals, Fujirebio, and Euroimmun. In the past 2 years, he has received consultancy/ speaker fees (paid to the institution) from Lilly, Rocha, and Fujirebio. Go to Neurology.org/N for full disclosures.

\section{Publication history}

Received by Neurology March 21, 2018. Accepted in final form October 3, 2018.

\section{References}

1. Jansen WJ, Ossenkoppele R, Knol DL, et al. Prevalence of cerebral amyloid pathology in persons without dementia: a meta-analysis. JAMA 2015;313:1924-1938.

2. Jack CR Jr, Wiste HJ, Weigand SD, et al. Age-specific and sex-specific prevalence of cerebral beta-amyloidosis, tauopathy, and neurodegeneration in cognitively unimpaired individuals aged 50-95 years: a cross-sectional study. Lancet Neurol 2017; 16:435-444.

3. Sperling RA, Aisen PS, Beckett LA, et al. Toward defining the preclinical stages of Alzheimer's disease: recommendations from the National Institute on Aging-Alzheimer's Association workgroups on diagnostic guidelines for Alzheimer's disease. Alzheimers Dement 2011;7:280-292.

4. Jack CR Jr, Holtzman DM. Biomarker modeling of Alzheimer's disease. Neuron 2013;80:1347-1358.

5. Nelson PT, Alafuzoff I, Bigio EH, et al. Correlation of Alzheimer disease neuropathologic changes with cognitive status: a review of the literature. J Neuropathol Exp Neurol 2012;71:362-381.

6. Ossenkoppele R, Schonhaut DR, Scholl M, et al. Tau PET patterns mirror clinical and neuroanatomical variability in Alzheimer's disease. Brain 2016;139:1551-1567.

7. Bejanin A, Schonhaut DR, La Joie R, et al. Tau pathology and neurodegeneration contribute to cognitive impairment in Alzheimer's disease. Brain 2017;140:3286-3300.

8. Jack CR Jr, Wiste HJ, Weigand SD, et al. Defining imaging biomarker cut points for brain aging and Alzheimer's disease. Alzheimers Dement 2017;13:205-216. 
9. Zhang X, Mormino EC, Sun N, et al. Bayesian model reveals latent atrophy factors with dissociable cognitive trajectories in Alzheimer's disease. Proc Natl Acad Sci USA 2016;113:E6535-E6544.

10. Jansen WJ, Ossenkoppele R, Tijms BM, et al. Association of cerebral amyloid-beta aggregation with cognitive functioning in persons without dementia. JAMA Psychiatry 2018;5:84-95.

11. Ossenkoppele R, van der Flier WM, Verfaillie SC, et al. Long-term effects of amyloid, hypometabolism, and atrophy on neuropsychological functions. Neurology 2014;82: 1768-1775.

12. Hedden $\mathrm{T}, \mathrm{Oh} \mathrm{H}$, Younger AP, Patel TA. Meta-analysis of amyloid-cognition relations in cognitively normal older adults. Neurology 2013;80:1341-1348.

13. Palmqvist $\mathrm{S}$, Zetterberg $\mathrm{H}$, Blennow $\mathrm{K}$, et al. Accuracy of brain amyloid detection in clinical practice using cerebrospinal fluid beta-amyloid 42: a cross-validation study against amyloid positron emission tomography. JAMA Neurol 2014;71:1282-1289.

14. Albert MS, DeKosky ST, Dickson D, et al. The diagnosis of mild cognitive impairment due to Alzheimer's disease: recommendations from the National Institute on AgingAlzheimer's Association workgroups on diagnostic guidelines for Alzheimer's disease. Alzheimers Dement 2011;7:270-279.

15. Dubois B, Feldman HH, Jacova C, et al. Advancing research diagnostic criteria for Alzheimer's disease: the IWG-2 criteria. Lancet Neurol 2014;13:614-629.

16. McKhann GM, Knopman DS, Chertkow H, et al. The diagnosis of dementia due to Alzheimer's disease: recommendations from the National Institute on Aging-Alzheimer's Association workgroups on diagnostic guidelines for Alzheimer's disease. Alzheimers Dement 2011;7:263-269.

17. Jessen F, Amariglio RE, van Boxtel M, et al. A conceptual framework for research on subjective cognitive decline in preclinical Alzheimer's disease. Alzheimers Dement 2014;10:844-852.

18. Jack CR Jr, Bennett DA, Blennow K, et al. NIA-AA Research Framework: toward a biological definition of Alzheimer's disease. Alzheimers Dement 2018;14:535-562.

19. Blennow K, Hampel H, Weiner M, Zetterberg H. Cerebrospinal fluid and plasma biomarkers in Alzheimer disease. Nat Rev Neurol 2010;6:131-144.

20. Spratt M, Carpenter J, Sterne JA, et al. Strategies for multiple imputation in longitudinal studies. Am J Epidemiol 2010;172:478-487.

21. Sled JG, Zijdenbos AP, Evans AC. A nonparametric method for automatic correction of intensity nonuniformity in MRI data. IEEE Trans Med Imaging 1998;17:87-97.

22. Segonne F, Dale AM, Busa E, et al. A hybrid approach to the skull stripping problem in MRI. Neuroimage 2004;22:1060-1075.

23. Fischl B, Salat DH, Busa E, et al. Whole brain segmentation: automated labeling of neuroanatomical structures in the human brain. Neuron 2002;33:341-355.

24. Fischl B, Dale AM. Measuring the thickness of the human cerebral cortex from magnetic resonance images. Proc Natl Acad Sci USA 2000;97:11050-11055.

25. Maass A, Landau S, Baker SL, et al. Comparison of multiple tau-PET measures as biomarkers in aging and Alzheimer's disease. Neuroimage 2017;157:448-463.

26. Rousset OG, Ma Y, Evans AC. Correction for partial volume effects in PET: principle and validation. J Nucl Med 1998;39:904-911.

27. Mattsson N, Smith R, Strandberg O, et al. Comparing (18)F-AV-1451 with CSF t-tau and p-tau for diagnosis of Alzheimer disease. Neurology 2018;90:e388-e395.

28. Mitchell TW, Mufson EJ, Schneider JA, et al. Parahippocampal tau pathology in healthy aging, mild cognitive impairment, and early Alzheimer's disease. Ann Neurol 2002;51:182-189.

29. Johnson KA, Schultz A, Betensky RA, et al. Tau positron emission tomographic imaging in aging and early Alzheimer disease. Ann Neurol 2016;79:110-119.

30. Scholl M, Lockhart SN, Schonhaut DR, et al. PET imaging of tau deposition in the aging human brain. Neuron 2016;89:971-982.
31. Jack CR Jr, Wiste HJ, Weigand SD, et al. Age-specific population frequencies of cerebral beta-amyloidosis and neurodegeneration among people with normal cognitive function aged 50-89 years: a cross-sectional study. Lancet Neurol 2014;13: 997-1005.

32. Iaccarino L, Tammewar G, Ayakta N, et al. Local and distant relationships between amyloid, tau and neurodegeneration in Alzheimer's disease. Neuroimage Clin 2018; $17: 452-464$.

33. LaPoint MR, Chhatwal JP, Sepulcre J, Johnson KA, Sperling RA, Schultz AP. The association between tau PET and retrospective cortical thinning in clinically normal elderly. Neuroimage 2017;157:612-622.

34. Braak H, Del Tredici K. The preclinical phase of the pathological process underlying sporadic Alzheimer's disease. Brain 2015;138:2814-2833.

35. Spillantini MG, Goedert M. Tau protein pathology in neurodegenerative diseases. Trends Neurosci 1998;21:428-433.

36. Terry RD, Masliah E, Salmon DP, et al. Physical basis of cognitive alterations in Alzheimer's disease: synapse loss is the major correlate of cognitive impairment. Ann Neurol 1991;30:572-580

37. Spires-Jones TL, Hyman BT. The intersection of amyloid beta and tau at synapses in Alzheimer's disease. Neuron 2014;82:756-771.

38. Phillips JS, Das SR, McMillan CT, et al. Tau PET imaging predicts cognition in atypical variants of Alzheimer's disease. Hum Brain Mapp 2018;39:691-708.

39. Giannakopoulos P, Herrmann FR, Bussiere T, et al. Tangle and neuron numbers, but not amyloid load, predict cognitive status in Alzheimer's disease. Neurology 2003;60: 1495-1500.

40. Jacobs HIL, Hedden T, Schultz AP, et al. Structural tract alterations predict downstream tau accumulation in amyloid-positive older individuals. Nat Neurosci 2018;21: 424-431.

41. Baker JE, Lim YY, Pietrzak RH, et al. Cognitive impairment and decline in cognitively normal older adults with high amyloid-beta: a meta-analysis. Alzheimers Dement (Amst) 2017;6:108-121.

42. Ossenkoppele R, Zwan MD, Tolboom N, et al. Amyloid burden and metabolic function in early-onset Alzheimer's disease: parietal lobe involvement. Brain 2012 135:2115-2125.

43. Frings L, Hellwig S, Spehl TS, et al. Asymmetries of amyloid-beta burden and neuronal dysfunction are positively correlated in Alzheimer's disease. Brain 2015;138: 3089-3099.

44. Rentz DM, Amariglio RE, Becker JA, et al. Face-name associative memory performance is related to amyloid burden in normal elderly. Neuropsychologia 2011;49: 2776-2783.

45. Palmqvist S, Scholl M, Strandberg O, et al. Earliest accumulation of beta-amyloid occurs within the default-mode network and concurrently affects brain connectivity. Nat Commun 2017;8:1214

46. Buckner RL, Snyder AZ, Shannon BJ, et al. Molecular, structural, and functional characterization of Alzheimer's disease: evidence for a relationship between default activity, amyloid, and memory. J Neurosci 2005;25:7709-7717.

47. Buckner RL, Andrews-Hanna JR, Schacter DL. The brain's default network: anatomy, function, and relevance to disease. Ann NY Acad Sci 2008;1124:1-38.

48. Johnson KA, Gregas M, Becker JA, et al. Imaging of amyloid burden and distribution in cerebral amyloid angiopathy. Ann Neurol 2007;62:229-234.

49. van der Flier WM, Skoog I, Schneider JA, et al. Vascular cognitive impairment. Nat Rev Dis Primers 2018;4:18003.

50. Sander K, Lashley T, Gami P, et al. Characterization of tau positron emission tomog raphy tracer $[(18) \mathrm{F}] \mathrm{AV}-1451$ binding to postmortem tissue in Alzheimer's disease, primary tauopathies, and other dementias. Alzheimers Dement 2016;12:1116-1124. 


\section{Neurology}

\section{Associations between tau, $\mathrm{A} \beta$, and cortical thickness with cognition in Alzheimer disease}

Rik Ossenkoppele, Ruben Smith, Tomas Ohlsson, et al.

Neurology 2019;92;e601-e612 Published Online before print January 9, 2019

DOI 10.1212/WNL.0000000000006875

\section{This information is current as of January 9, 2019}

\section{Updated Information \&} Services

References

Citations

Subspecialty Collections

Permissions \& Licensing

Reprints including high resolution figures, can be found at: http://n.neurology.org/content/92/6/e601.full

This article cites 50 articles, 8 of which you can access for free at: http://n.neurology.org/content/92/6/e601.full\#ref-list-1

This article has been cited by 9 HighWire-hosted articles: http://n.neurology.org/content/92/6/e601.full\#\#otherarticles

This article, along with others on similar topics, appears in the following collection(s):

All Neuropsychology/Behavior

http://n.neurology.org/cgi/collection/all_neuropsychology_behavior Alzheimer's disease

http://n.neurology.org/cgi/collection/alzheimers_disease

MCI (mild cognitive impairment)

http://n.neurology.org/cgi/collection/mci_mild_cognitive_impairment MRI

http://n.neurology.org/cgi/collection/mri

PET

http://n.neurology.org/cgi/collection/pet

Information about reproducing this article in parts (figures,tables) or in its entirety can be found online at:

http://www.neurology.org/about/about_the_journal\#permissions

Information about ordering reprints can be found online:

http://n.neurology.org/subscribers/advertise

Neurology ${ }^{\circledR}$ is the official journal of the American Academy of Neurology. Published continuously since 1951, it is now a weekly with 48 issues per year. Copyright Copyright (C) 2019 The Author(s). Published by Wolters Kluwer Health, Inc. on behalf of the American Academy of Neurology.. All rights reserved. Print ISSN: 0028-3878. Online ISSN: 1526-632X.

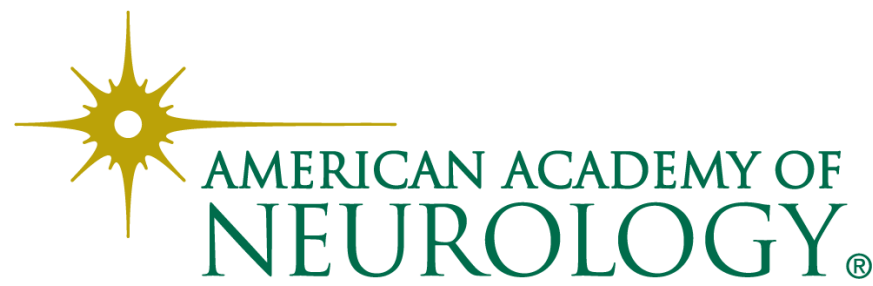

